\title{
Sediment records in the river Loire estuary
}

\author{
J.L. Reyss ${ }^{1,3}$, F. Siclet ${ }^{2}$ and C. Cazala ${ }^{1}$ \\ ${ }^{1}$ Laboratoire des Sciences du Climat et de l'Environnement, Laboratoire Mixte CEA-CNRS, \\ 91198 Gif-sur-Yvette cedex, France \\ ${ }^{2}$ EDF R\&D Département Laboratoire National d'Hydraulique et Environnement, \\ BP. 49, 78401 Chatou cedex, France \\ ${ }^{3}$ Laboratoire Souterrain de Modane, 90 rue Polset, 73500 Modane, France
}

\begin{abstract}
Within the framework of the "Loire river and estuary radioecology" program, radionuclide measurements were undertaken in the various components of the estuarine aquatic ecosystem: dissolved, particulate and sedimentary fractions. In order to investigate the extent of long-term radionuclide accumulation in this area, 8 sediment cores were sampled in the estuary, plus 2 cores on the sea shore near the river mouth; gamma spectrometric measurements were performed at the Laboratoire Souterrain de Modane (LSM., CNRS-CEA) in the French Alps using very low background, high efficiency "well-type" Ge detectors with crystal volumes of 430 and $910 \mathrm{~cm}^{3}$. Such large detectors allow the measurement of samples of about $20 \mathrm{~g}$ with very high detection efficiencies. Among the artificial radionuclides present in industrial releases, ${ }^{60} \mathrm{Co}$ was detected in most samples throughout the cores. Using ${ }^{137} \mathrm{Cs}$ and ${ }^{210} \mathrm{~Pb}$ profiles in the cores, mean apparent accumulation rates were estimated after a normalization to the fine-grain sedimentary fraction which is the main carrier of reactive radionuclides. A sedimentary record of the last 50 years was obtained. ${ }^{60} \mathrm{Co}$ activities were always very low, from below 0.1 up to 2 Bq.kg ${ }^{-1}$. Plots of ${ }^{60} \mathrm{Co}$ versus sedimentary layer ages are presented and compared with annulal discharges of nuclear power plants located along the Ioire river.
\end{abstract}

\section{INTRODUCTION}

Receiving the discharge of 14 nuclear reactors, the Loire river estuary, one of the main riverine input to Atlantic Ocean, may have recorded the industrial releases since the beginning of the nuclear fuel use in the sixties. Sediments deposited in the estuary bed contain long half lived radionuclides like ${ }^{60} \mathrm{Co}$ which can be considered as a tracer of such discharges. Simultaneous determination of sediments deposition rates and radioactive tracers contents would allow a reconstruction of the long term impact of nuclear industries to the environment.

Such data are also necessary for the understanding of radionuclides exchange processes in the turbidity maximum zone at the interface between fresh and marine waters.

The aim of the present work is to constrain the sediment deposition history and to measure the very ${ }^{10}{ }^{60} \mathrm{Co}$ activities in several cores sampled at different sites in the estuary (from the river to the sea, fluvio estuary zone, internal estuary and external estuary).

\section{METHOD}

\subsection{Sampling}

During 8 field campaigns conducted between 1998 and 1999, 10 sedimentary cores were sampled (figl). ICS, 1CSB, 2CC, 2CT, were taken at low tide using a hand-driven tube $(1.4 \mathrm{~m}$ length $\mathrm{x} 10 \mathrm{~cm}$ in 
diameter) whereas the others were abtained by diving with a $5 \mathrm{~cm}$ in diameter corer (IFREMER). Only the 5 most representative cores are reported in the present work (2CT, 1CM, 1CE, 1CP, 1CS).

In the laboratory the sediment was extruded, oven-dried at $110^{\circ} \mathrm{C}$ for 24 hours and stored in polypropylene tubes ready for non destructive gamma spectrometry investigation.

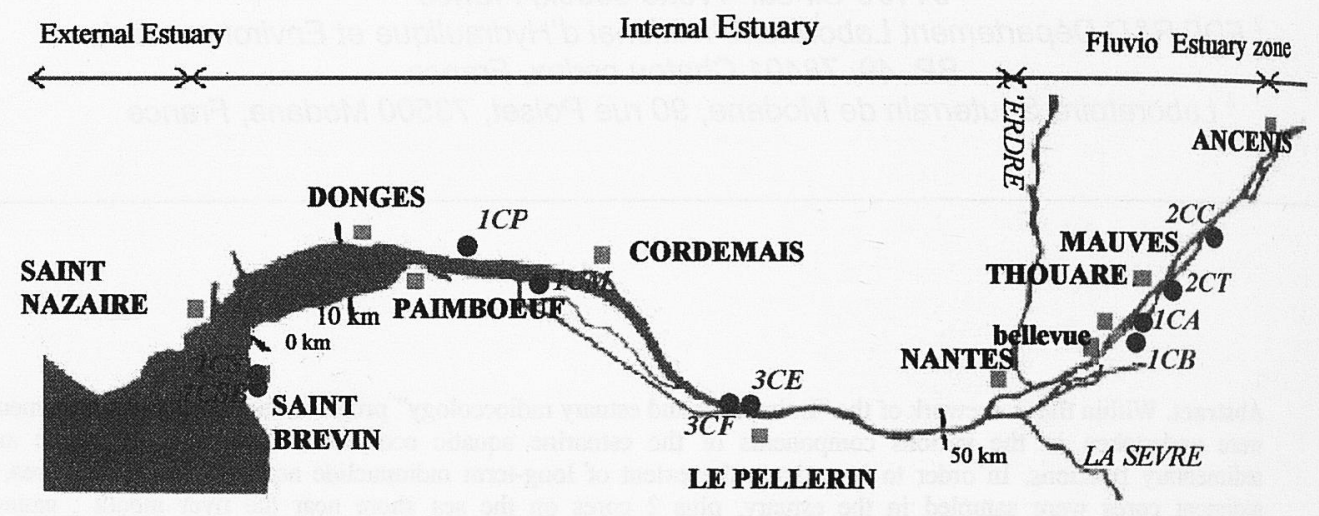

Fig 1 : Map of sampling sites in the Loire river estuary.

\subsection{Gamma spectrometry}

Multi-elementary analyses were performed at the Laboratoire Souterrain de Modane (LSM, CNRS-CEA) in the French Alps [1] using very low background, high efficiency "well type " detectors with germaniun crystal volumes of 430 and $910 \mathrm{~cm}^{3}$. A spectrum obtained by measuring during 2 days $26 \mathrm{~g}$ of a sediment sample containing $2 \mathrm{~Bq} \cdot \mathrm{kg}^{-1}$ of ${ }^{60} \mathrm{Co}$ is shown in fig 2 .A zoom on the ${ }^{60} \mathrm{Co}$ sum peak at $2505 \mathrm{keV}$ is also displayed. Specific activities of ${ }^{210} \mathrm{~Pb},{ }^{234-228} \mathrm{Th},{ }^{226-228} \mathrm{Ra},{ }^{40} \mathrm{~K},{ }^{7} \mathrm{Be},{ }^{137-134} \mathrm{Cs},{ }^{60} \mathrm{Co},{ }^{110}{ }^{n t} \mathrm{Ag}$ were determined.

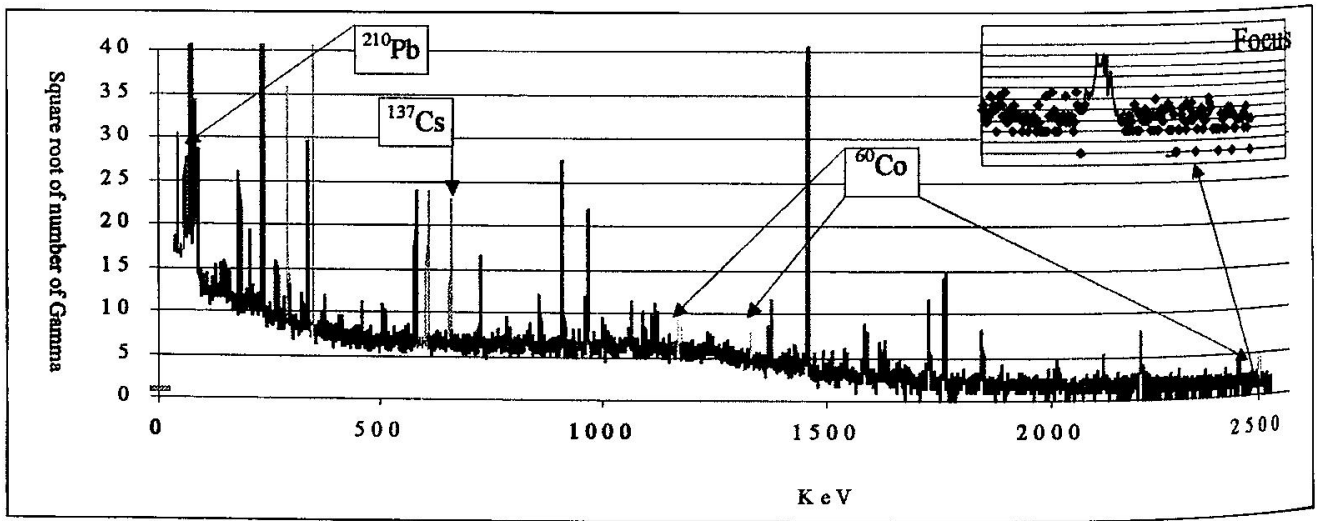

Fig 2 : Gamma spectrum obtained by measuring during 2 days $26 \mathrm{~g}$ of a sediment sample containing 2 Bq.kg ${ }^{-1}$ of ${ }^{60} \mathrm{C}$ 


\subsection{Granulometry}

Particle size distribution was analyzed on few dried sediments samples by laser beam diffraction with a Coulter particle size analyzer.

\section{RESULTS}

\subsection{Sediment deposition rates}

${ }^{210} \mathrm{~Pb}_{\mathrm{exc}}$ decay method often used to assess the recent sedimentation rates in lakes, rivers and sea [2] [3], cannot be applied in the present study because radionuclides of interest are known to be carried by small particles which may be diluted in variable amount by detrital coarse fraction (fig 3A). Atmospheric reactive products like ${ }^{210} \mathrm{~Pb}$ are rapidly adsorbed and then transported by the fine fraction [4]. Therefore a normalization of ${ }^{210} \mathrm{~Pb}$ excess to this fraction is necessary in order to obtain a regular trend in ${ }^{210} \mathrm{~Pb}$ profile versus depth.

Granulometric study was not conducted on all samples, so it was necessary to find a correlation between granulometry and another parameter systematically measured i.e a gamma emitter radionuclide. The atmospheric nuclear test products ${ }^{137} \mathrm{Cs}$ is a good candidate for this purpose [5]. We plotted in (fig 3B) the relation between ${ }^{137} \mathrm{Cs}$ specific activities and the fine fraction $(<63 \mu \mathrm{m})$ contents for our available data. Using this relation assumes a constant supply of ${ }^{137} \mathrm{Cs}$ to the sediment during the time period studied (1960-1998). The quite good determination coefficient $\left(R^{2}=0.88\right)$ validates this assumption which implies that Chernobyl peak (1986) and atmospheric test peak in the sixties are not important in this western part of France.

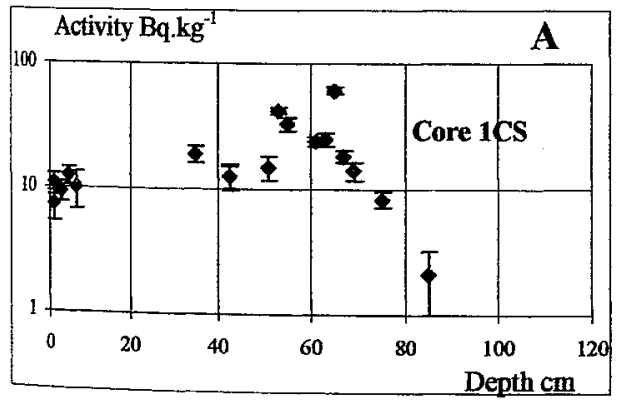

Fig 3A: ${ }^{210} \mathrm{~Pb}_{\text {exc }}=f($ depth $)$

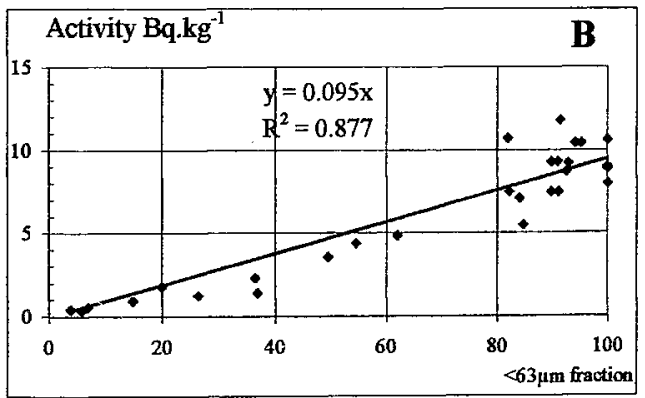

Fig $3 B:{ }^{137} \mathrm{Cs}=\mathrm{f}(\%<63 \mu \mathrm{m}$ fraction $)$

The result of this normalization of ${ }^{210} \mathrm{~Pb}$ to ${ }^{137} \mathrm{Cs}$ for the five sediment cores is shown in fig 4 . Except for core 1CM in the mud deposit which corresponds to a very young sediment, averaged deposition rates of few $\mathrm{cm} \cdot \mathrm{a}^{-1}$ can be proposed. In core $1 \mathrm{CS}$ the depth of ${ }^{137} \mathrm{Cs}$ appearance at $90 \mathrm{~cm}$ corresponding to the atmospheric weapon tests of the sixties confirms the accuracy of the method used giving an averaged sedimentation rate that compares well with the one obtained with ${ }^{210} \mathrm{~Pb}$. 
Normalized ${ }^{210} \mathbf{P b}_{\text {exc }}$ $=\mathbf{f}(\mathrm{d})$
$\mathbf{S}=$ averaged sedimentation rate
Normalized ${ }^{60} \mathrm{Co}$

$\operatorname{activities}\left(\mathbf{t}_{0}\right)=\mathbf{f}(\mathbf{d})$
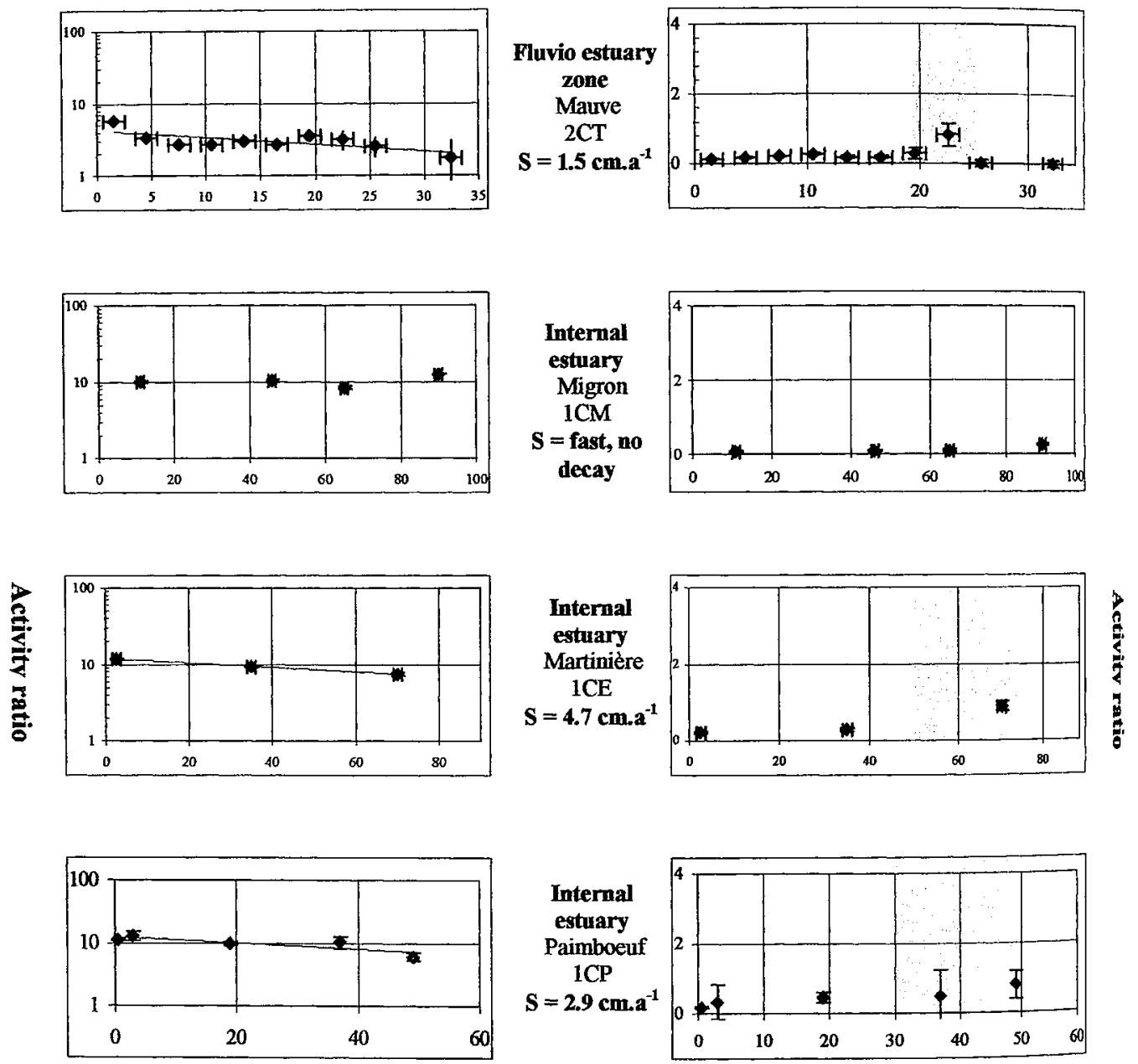

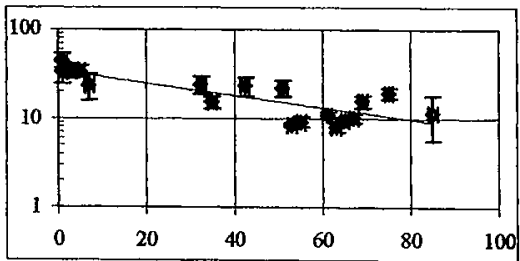

Depth cm

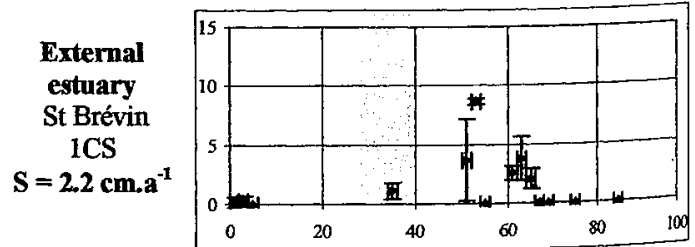

Depth cm

Fig 4 : Left : plots of ${ }^{210} \mathrm{~Pb}_{\text {exc }}$ normalized to ${ }^{137} \mathrm{Cs}$ (activity ratio) versus depth $(\mathrm{cm})$ in the five studied cores and deduod average sedimentation rates. Right; corresponding plots of ${ }^{60} \mathrm{Co}\left(\mathrm{t}_{0}\right)$ normalized to ${ }^{137} \mathrm{Cs}$ (activity ratio). Grey area mats the 1982-1986 years. 


\section{$3.2^{60} \mathrm{Co}$ distribution with depths in cores.}

For the same reason as for ${ }^{210} \mathrm{~Pb},{ }^{60} \mathrm{Co}$ activities were normalized to the fine fraction via ${ }^{137} \mathrm{Cs}$. Using the age of sediment horizons derived from the average sedimentation rates, ${ }^{60} \mathrm{Co}\left(\mathrm{T}_{1 / 2}=5.7 \mathrm{a}\right)$ activities have been corrected for decay for the time of deposition in the different cores (fig 4 Right).

We observe that ${ }^{60} \mathrm{Co}\left(\mathrm{t}_{0}\right)$ is not constant with depth in the cores. Using the sedimentation rate estimates the ${ }^{60} \mathrm{Co}$ maxima corresponds to the major industrial discharge period (grey area in fig 4 Right), between 1982-1986 except for core 1CS for which the ${ }^{60} \mathrm{Co}$ peak is dated between 1970 and 1976. This core was sampled on a beach exposed to the oceanic tides and waves, therefore the assumption of a constant sedimentation rate is probably an approximation. Fast deposition or erosion could drastically change the process. Under this peak a decrease of ${ }^{60} \mathrm{Co}$ activities is observed.

\section{CONCLUSION}

During the "Loire river and estuary radioecology" program, we measured the mean apparent sedimentation rates in four cores at different sites in the estuary. Because of the highly variable mineralogical and granulometrical composition of sediments a normalization of ${ }^{210} \mathrm{~Pb}_{\text {exc }}$ chronometer to the fine fraction was necessary. This normalization was conducted using a linear relation between ${ }^{137} \mathrm{Cs}$ and per cent $<63 \mu \mathrm{m}$ fraction. ${ }^{60} \mathrm{Co}$ depth profiles were interpreted in relation with the major industrial discharge period (1982-1986). After this period, ${ }^{60} \mathrm{Co}$ activity decreases and reaches values as low as 1 $\mathrm{Bq} . \mathrm{kg}^{-1}$ for the surface sediment.

\section{Acknowledgements \\ We are grateful to $\mathrm{C}$. Riccio for technical support at the LSM laboratory and $\mathrm{K}$. Varain for field campaigns help.}

\section{REFERENCE}

[1] Reyss J-L et al. Nucl.Inst.and Meth. A 357 (1995) 391-397.

[2] Appleby P.G. and Oldfiel F. « Application of lead 210 to sedimentation studies ", uranium-series desiquilibrium: Application to Earth, Marine, and environmental Sciences (Clarendon Press, Oxford, 1992) 731-778.

[3] Krishnaswamy et al. Earth Planet. Sci.Lett 11 (1971). 407-414 .

[4] Schmidt et al this issue.

[5] Bonté et al. Acta Geologica Hispanica V.35 (2000) 339-355. 